\title{
Fiestas, vírgenes, juegos y rituales de agua en la comarca de Aracena
}

Pedro A. Cantero. Dpto. Ciencias Sociales. U. Pablo de Olavide

Hoy en día las fiestas

del agua han perdido

su eficacia simbólica;

en la mayoría el ritual

ha sido desplazado

por el juego
Origen y vehículo de toda vida, en la tradición judeo cristiana, el agua simboliza el arranque de la creación. El agua es madre y matriz, y como tal se la consideró como una teofanía. Empero, lo mismo que da vida la arrebata. Creadora y destructora. Una fuente era el centro del Paraíso terrenal, al pie del árbol del Bien y del Mal, fuente de vida, de inmortalidad, de juventud y de enseñanza. Los pozos y fuentes fueron en nuestra tierra puntos de reunión y regocijo, los puntos de agua jugaron un papel incomparable. En sus cercanías brotaba el amor y se iniciaban los noviazgos. Pero al mismo tiempo que enlaza, el agua separa, de ahí que fuera particularmente útil en los rituales de paso. A la par del fuego, el agua fue un elemento ritual de purificación; por su poder lustral reajustaba todo desarreglo.

\section{Rituales de agua}

Si antaño el agua estuvo en el centro de sobrados rituales que acompañaban la vida de los hombres, hoy se puede decir que bien pocos restan, por haber perdido su eficacia simbólica, y, no obstante, el agua ha redoblado su papel lúdico. Los juegos de agua son un elemento de diversión muy apreciado en la vida moderna, sin embargo, en la mayoría de las fiestas del agua, el ritual ha sido desplazado por el juego. La utilización del agua en los rituales se debía a tres razones fundamentales: por ser el agua origen de vida, por su fuerza regeneradora y sobre todo por su poder lustral. Por el contacto con el agua se intenta vivificar y captar la fuerza intrínseca de la fuente, del río o de los objetos sagrados sumergidos en ella; pero, sobre todo, se espera limpiar toda inmundicia o, lo que es más, liberar de todo resto anterior, aun sagrado. El agua lustral surge al estado natural o se fabrica. Por lo general, las agua vivas poseen ese poder: la mayoría de los manantiales, algunos ríos y arroyos, así como ciertos pozos. Las maneras de fabricar el agua purificadora son diversas, con ciertas plantas la noche de San Juan o con imágenes u objetos sagrados, siendo entre nosotros la más difundida la bendición de Pascua, tras la inmersión del cirio encendido con el nuevo fuego. El ritual pascual es de una gran intensidad simbólica y así lo comprendieron nuestros antepasados prestando a ese día y a los elementos que intervenían en la velada un poder de especial eficacia. Con el agua ya bendecida el oficiante asperja abundantemente a los fieles como forma de purificación y vínculo con el Padre. El agua y las velas encendidas con aquella llama se llevaban a casa y se utilizaban en momentos críticos. 


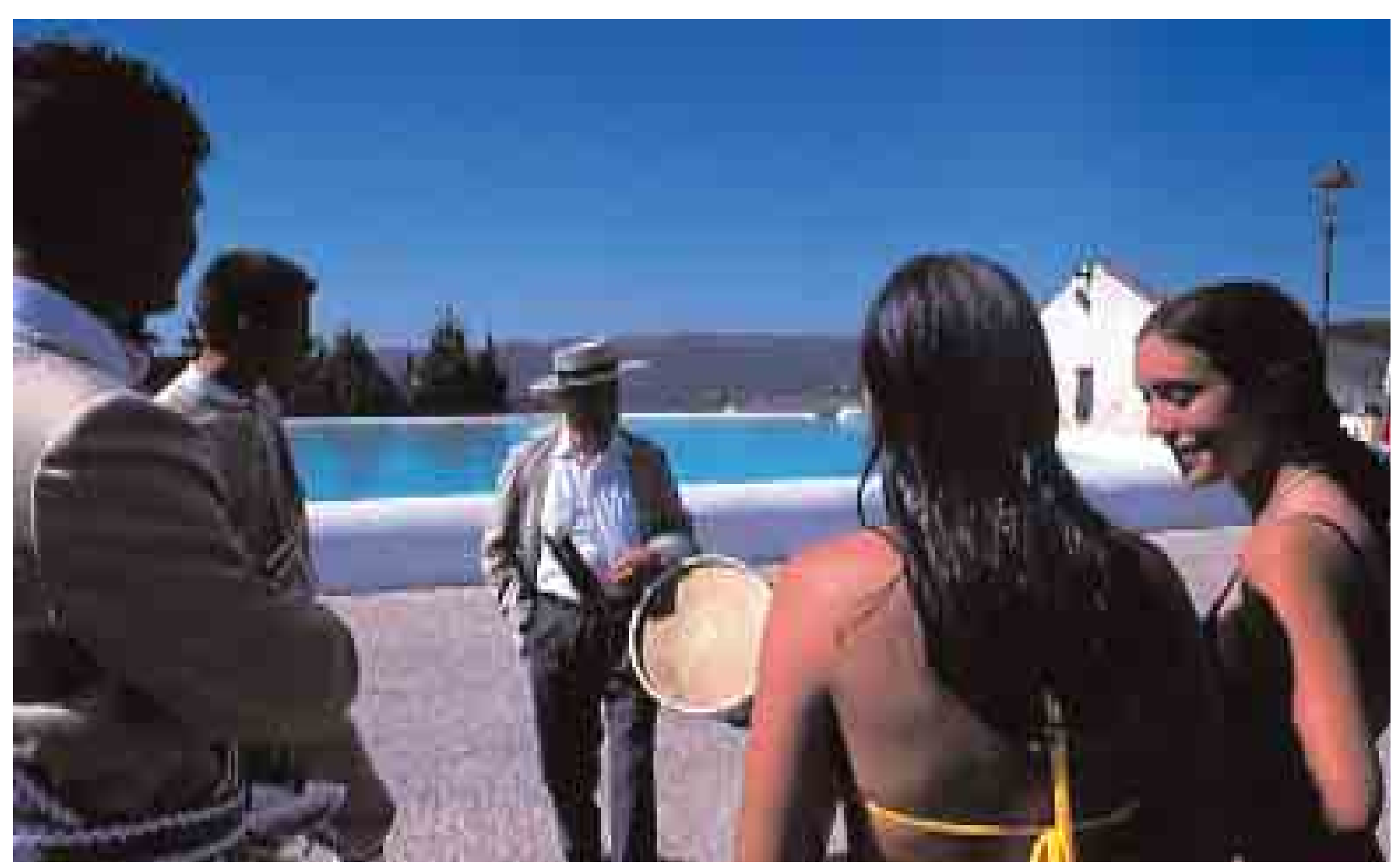

(1) Laguna de Cañaveral de León en la fiesta de Sta. Marina / JAVIer AndradA 


\section{El voluntariado responsable}

En mil novecientos noventa y siete un grupo de jóvenes preocupados por el patrimonio y el medio ambiente deciden constituir una asociación juvenil y desarrollar diferentes actividades. Con el paso del tiempo empiezan a trabajar con más colectivos y en el año dos mil forman una nueva asociación, Alma Natura (www.almanatura.org), para perseguir objetivos culturales (relativos a la recuperación y difusión del patrimonio cultural de la Sierra de Aracena y Picos de Aroche), y también relacionados con el medio ambiente, con la enseñanza del respeto a la Naturaleza y con lograr la compatibilidad del uso social, recreativo y cultural que se haga del medio natural.

Alma Natura también cuenta con objetivos de contenido social, trabajando para paliar el desarraigo de las comunidades rurales, favoreciendo su progreso y apoyando a otras asociaciones con inquietudes semejantes. Del mismo modo, entre los fines que persigue la asociación cabe destacar la búsqueda de la innovación pedagógica en los diferentes ámbitos de la educación tanto formal como la informal, así como la promoción del deporte como vehículo de mejora del estado de salud de niños y mayores a través de juegos poco conocidos o alternativos.

Las principales actividades que desarrolla la asociación se enmarcan dentro de la ejecución de diferentes proyectos de voluntariado cultural y ambiental, tales como senderismo, cicloturismo o recorridos a través de las rutas patrimoniales diseñadas sobre los Molinos de Agua existentes en Arroyomolinos de León, lugar donde la asociación tiene su sede. Entre los proyectos ya ejecutados, se debe a Alma Natura la organización de las XXI Jornadas del Patrimonio de la Comarca de la Sierra de Huelva en 2006, un evento que contó también con la colaboración del Ayuntamiento y de todos los colectivos sociales de este municipio serrano.

En relación con los Molinos de Agua de Arroyomolinos, a su protección y conservación, se ha elaborado un inventario que sirvió para evaluar aspectos como el número, la estructura y el estado de conservación. Este primer acercamiento a los molinos se convirtió posteriormente en un documento técnico cuyo fin es la Inscripción Genérica Colectiva de los mismos en el Catálogo General del Patrimonio Histórico Andaluz.

Mediante otros proyectos de voluntariado, como el ambiental, se realizó también la mejora y el acondicionamiento de los entornos fluviales de los Molinos de Agua, se limpiaron de maleza y basuras para que el acceso a los mismos se hiciera más fácilmente y, hoy día, se siguen realizando actividades con el objetivo de recuperar y promocionar ese patrimonio.

Asociación Alma Natura 


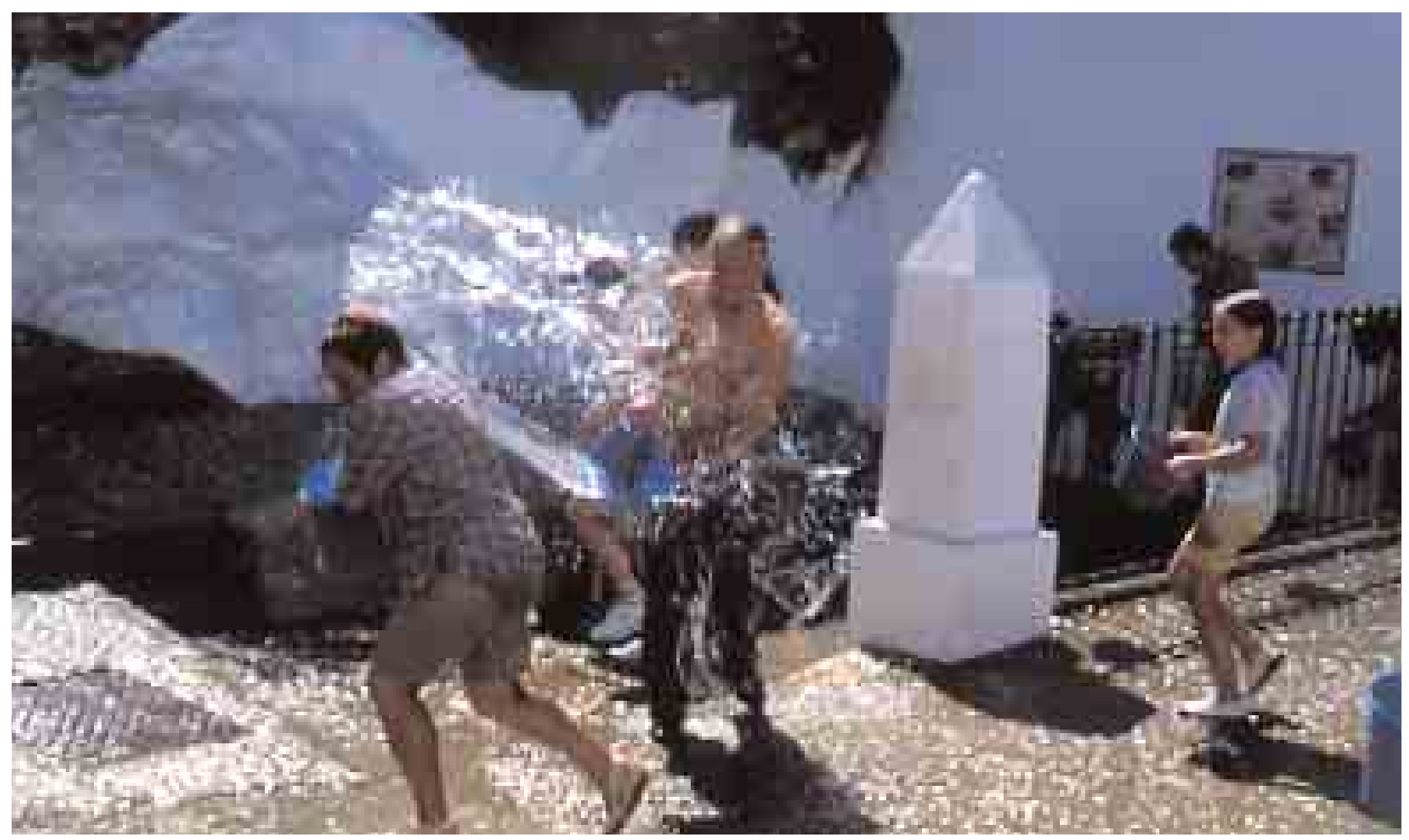

(1) Fiesta de los Jarritos. Galaroza / JAVIER ANdRAdA

Entre los rituales de agua que propiciaban o precipitaban el encuentro están las luchas simbólicas, que mucho tenían de subversión lúdica. Se dio en diversos lugares de Andalucía el de romper cacharros de agua, unas veces para propiciar el contacto entre chicos y chicas, otras como inversión carnavalesca o para confirmar noviazgo. Entre las formas de romper la barrera sexual he encontrado ejemplos distintos que perduran en nuestra provincia: en Galaroza, el 6 de setiembre, en los alrededores de la Fuente de los Doce Caños, se compraban los cacharros a los alfareros que pasaban camino del Santuario de Alájar; los mozos mojaban a las mozas con piporros y éstas debían rompérselo de un puñetazo. Los zagales aprovechaban el cuerpo a cuerpo para tocar a las muchachas. Fiesta eminentemente lúdica que se \|lamó de "los Jarritos" y que aún sigue practicándose con los cambios inherentes a la época. Un juego similar, "los Jarros", se viene haciendo en Cumbres Mayores a mediados de agosto. Hoy día, "la mojá" de la gente joven se hace la noche del 14 al 15, mientras que el día de la Virgen, al mediodía, son los niños, sobre todo, quienes se divierten echándose agua y mojando a los mayores que se dejan. Ni en una ni en otra los recipientes de barro juegan ya un rol central, pero en sus nombres guardan el viejo ritual. 


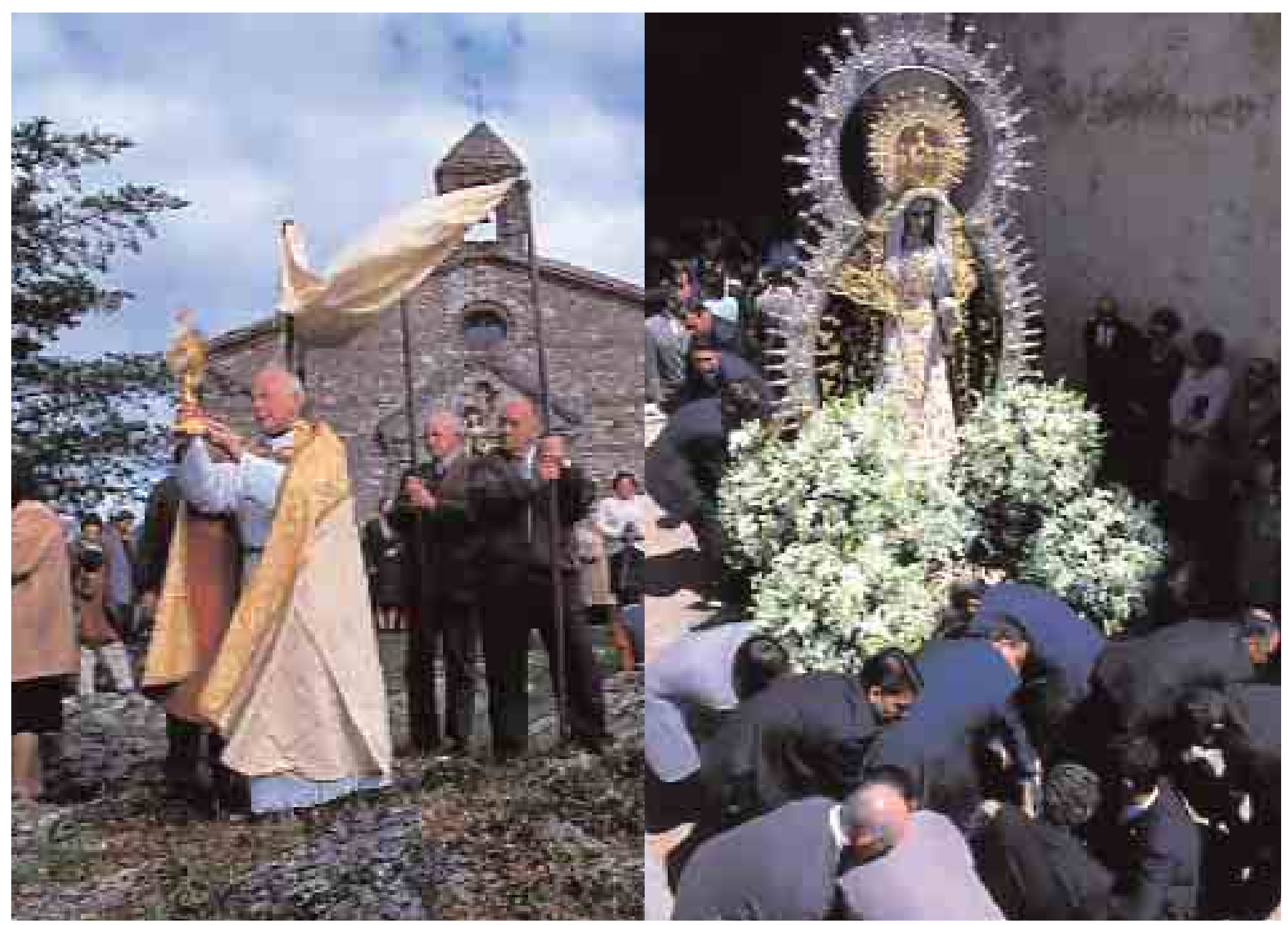

( B Bendición de las Huertas desde Sta. Brígida. Galaroza / JAVIER AndRADA

(1) Virgen de la Esperanza. Cumbres Mayores / JAVIER AndRAdA

Fiestas y juegos de agua

Descuidada la fuerza del rito queda viva la del juego, que nunca se perdió. Los juegos de agua siguen latentes en el corazón de toda fiesta; ellos forman parte del protocolo o irrumpen desordenando una solemnidad innecesaria, rompiendo un aburrimiento incipiente o abriendo perspectivas lúdicas. Adultos y jóvenes echan mano del agua si se presenta la ocasión, pero son éstos a quien ella llama en prioridad, de ahí que las fiestas de juego y agua sean las particularmente atractivas para la juventud. Ésta se crece en zambullidas que sólo encuentran cauce en su propia estela. Jugar no es un medio, jugar es el fin último. Al contrario del simulacro que pueda centrar otras diversiones, en el agua todo es verdad, no hay nada que se le resista, como el mismo frenesí de la danza que sólo para con el fin de la melodía, con el agotamiento del ritmo, los juegos de agua tienden a prolongarse. El gozo del agua tiene difícil competidor, sólo el otro gran juego, el que Eros comanda, lo supera, aunque el mismo agua está tan vinculada a Eros que los griegos hacían nacer a Afrodita de las ondas. De ahí que el agua venza al tiempo, lo suspenda.

En nuestra provincia no son pocas las fiestas en las que el agua encuentra cabida, porque sea toda la fiesta su goce, porque se centren en un paraje de aguas o por irrumpir el agua ocasional o perversa, para mayor deleite de quienes con ella se gozan. Si en la Sierra son más limitadas, no por ello dejan de ser más significativas. En primer lugar contamos con dos fiestas centradas sobre el agua misma y giras que se acercan a ella como renuevo del vínculo entre el hombre y la fertilidad que ella representa $y$, en segundo lugar, muchas de 


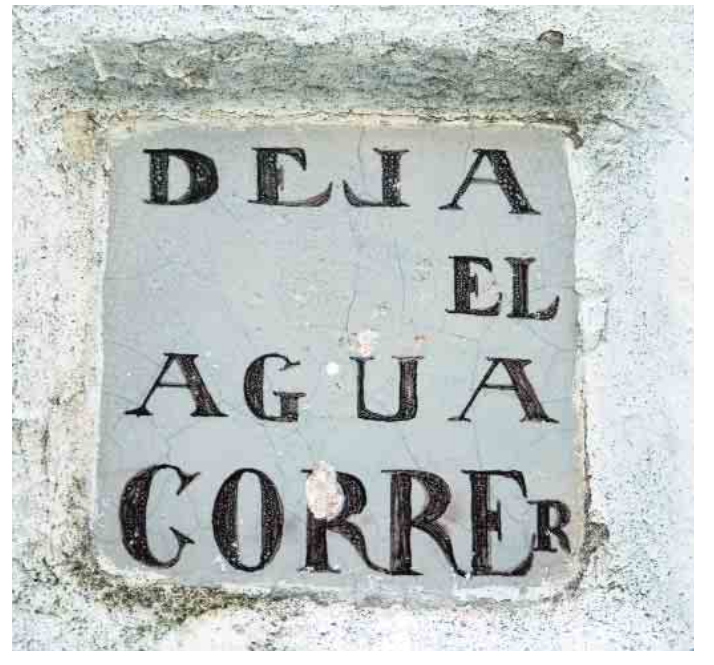

(1) Detalle de la Fuente. Aracena / Javier Romero, IAPH tenerla cerca en caso de que el mal acosara. No era menos apreciada, aunque por distinto motivo, aquel agua de San Juan de la que tan buenos recuerdos guardan en muchos pueblos. En diversas localidades de la provincia fue tenida por agua de juventud, tanto la procedente del rocío de ese mismo amanecer como la que pasó la noche en maceración de cinco plantas propiciatorias. El agua recogida la noche de San Juan ("La flor del agua") de ciertas fuentes y pozos tenía poder para hacer casar o ser feliz en amores. ¡Cuántos noviazgos comenzaron yendo a lavarse a la fuente esa noche! En La estación de Amor, se encuentran diversas referencias a este tipo de rituales en aquel día, con ejemplos onubenses notorios: «Creen las andaluzas [...] que en un barreño de agua clara pueden llegar a ver el rostro del novio futuro la noche de San Juan». Caro Baroja relata la técnica de arrojar agua y pedir el nombre: «El rito adivinatorio de arrojar agua por la ventana y preguntar el nombre al primero que pasa, para saber el nombre del novio, se lleva a cabo en Andalucía aún hoy, según he podido comprobar. [...] La víspera de San Juan a medianoche se llevaban a cabo allí adivinaciones de todas estas suertes: [...] Con plomo derretido y echado sobre agua. [...] Arrollando papeles con varios nombres y echándolos en un vaso de agua se adivina el nombre del novio cogiendo el que flota. [...] Arrojando el agua a la calle cuando pasa un mozo, que dice un nombre, se averigua también el nombre del novio» (CARO BAROJA, 1992: 299-307).

¿Qué queda de todo ello? La cultura del agua está experimentando transformaciones tanto más importantes cuanto que los usos del agua cambiaron radicalmente, pero su fuerza evocadora y su poder lúdico nos interpelan aun sin entenderlos. Si pudiéramos sabernos deudores de ella y reconocerla en nuestros gestos festivos o cotidianos ya tendríamos de qué sentirnos suyos. Le queda tanto más futuro al agua que, como bien escaso, pronto sabremos devolverle su rol primordial: dadora de vida, elemento de gozo. 


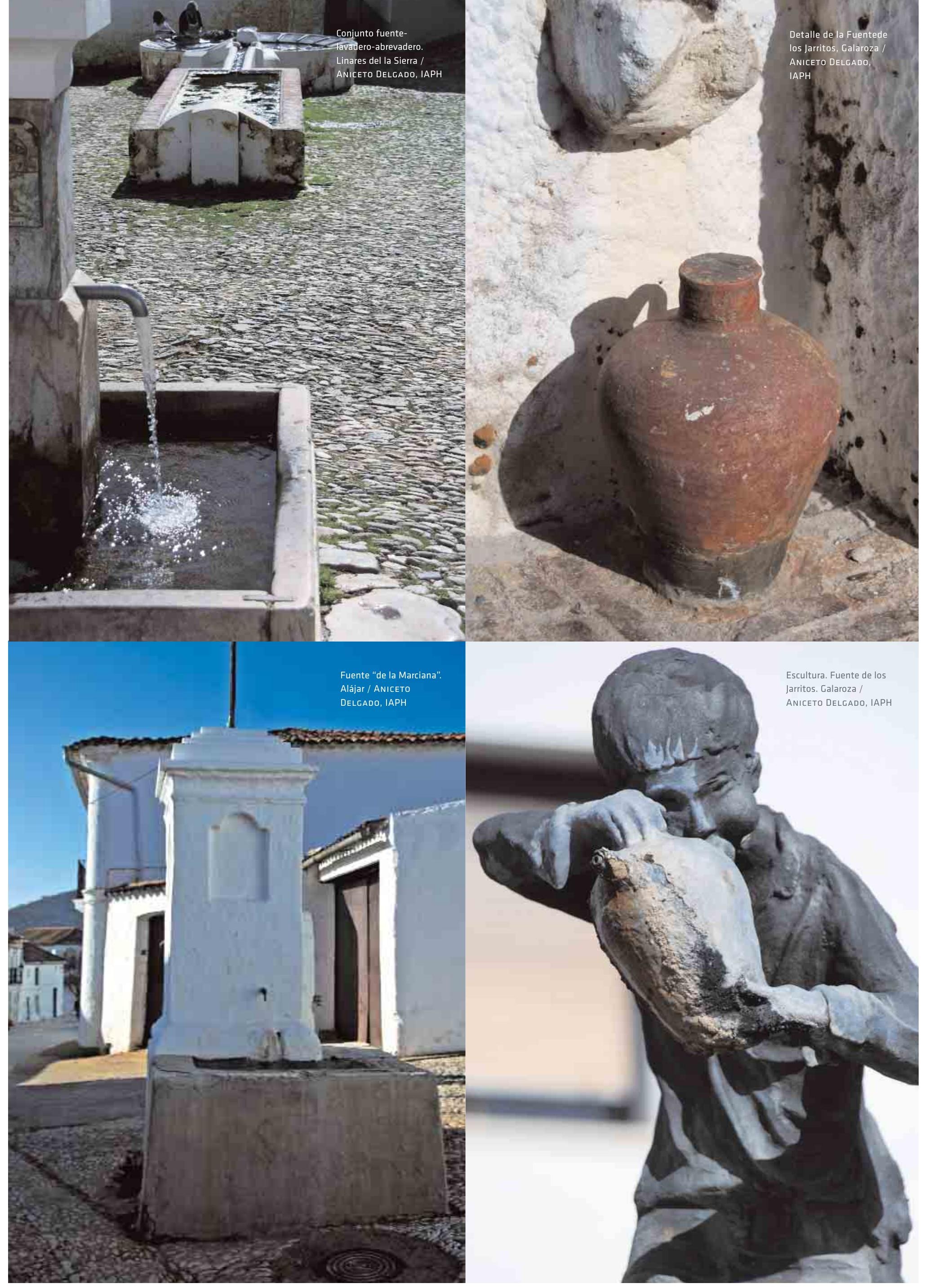




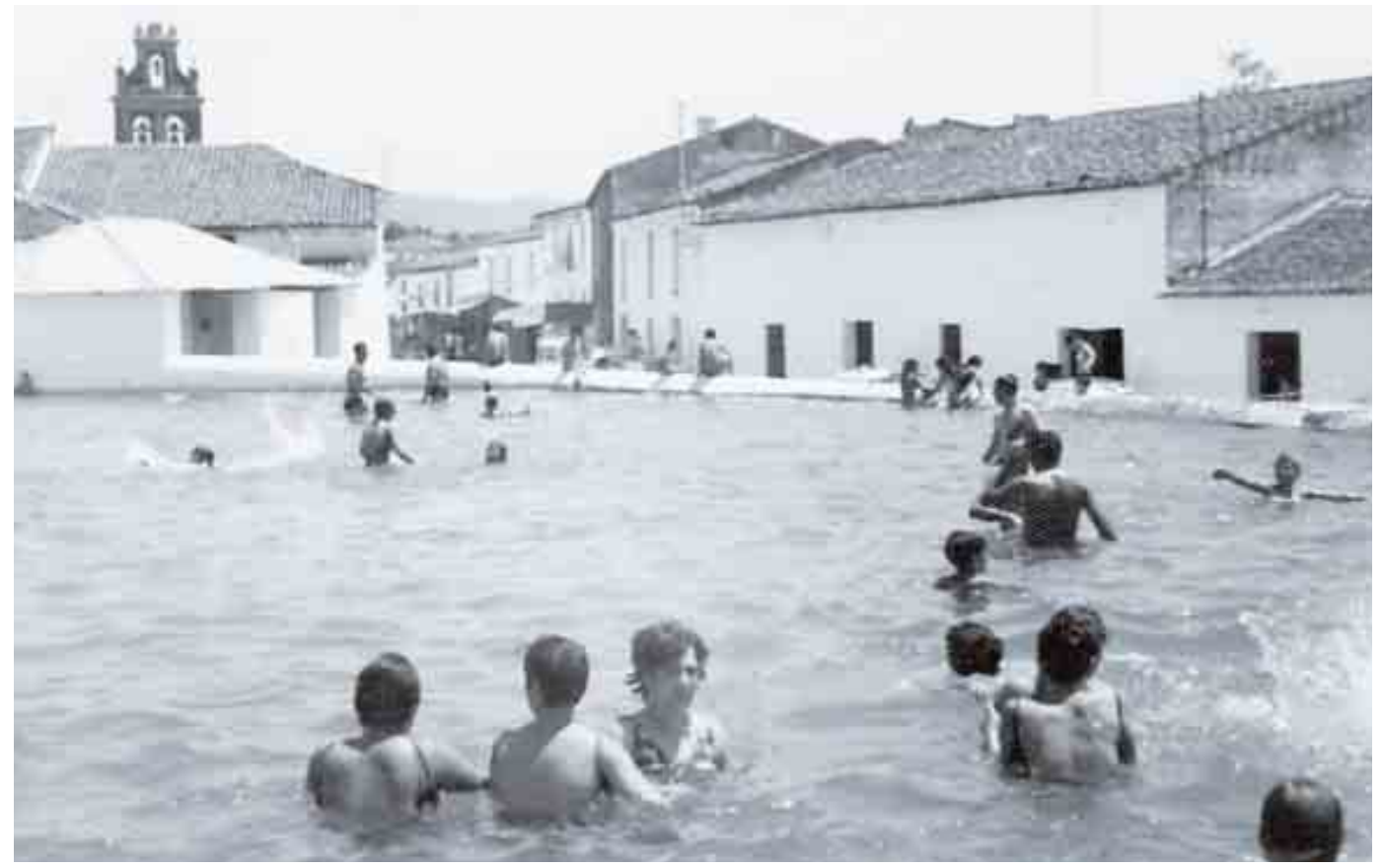

(1) La Laguna. Cañaveral de León. Años 60 / Donante: Antonio VÁzọuez Domínguez

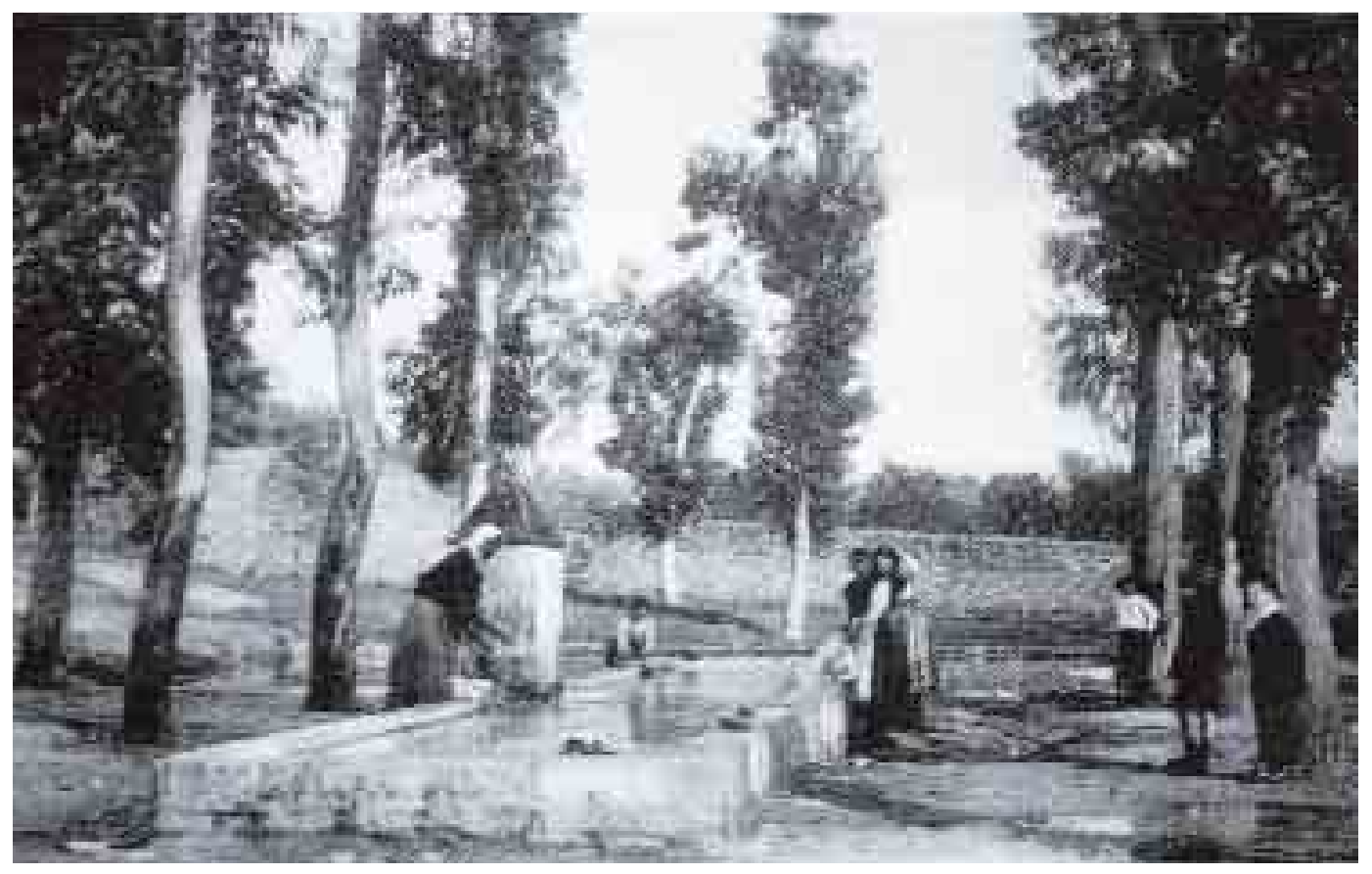

(1) Fuente de La Alguera. Aracena / Donante: MARio Rodrícuez 


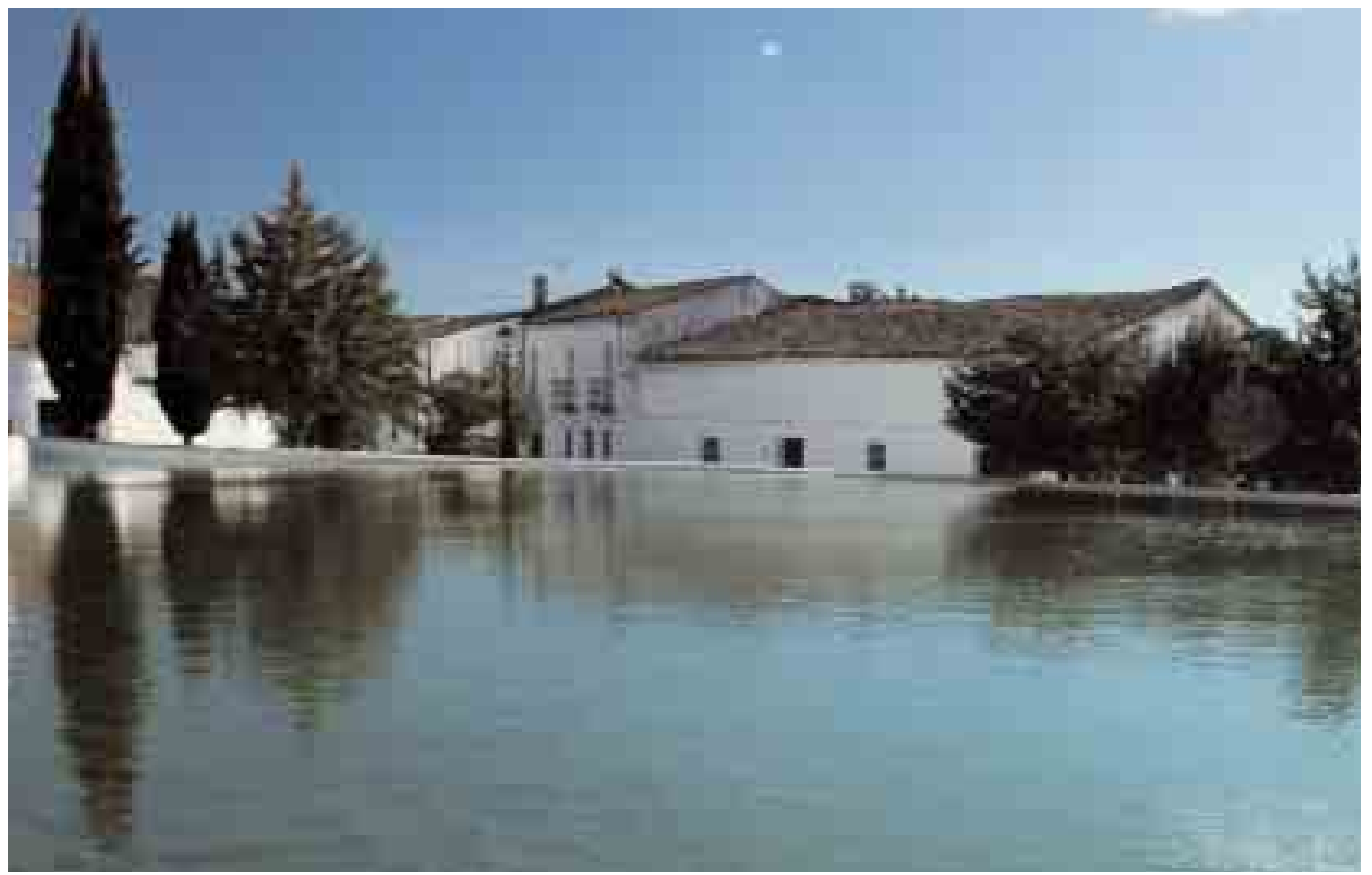

(1) La Laguna. Cañaveral de León. 2007 / JAVIER Romero, IAPH

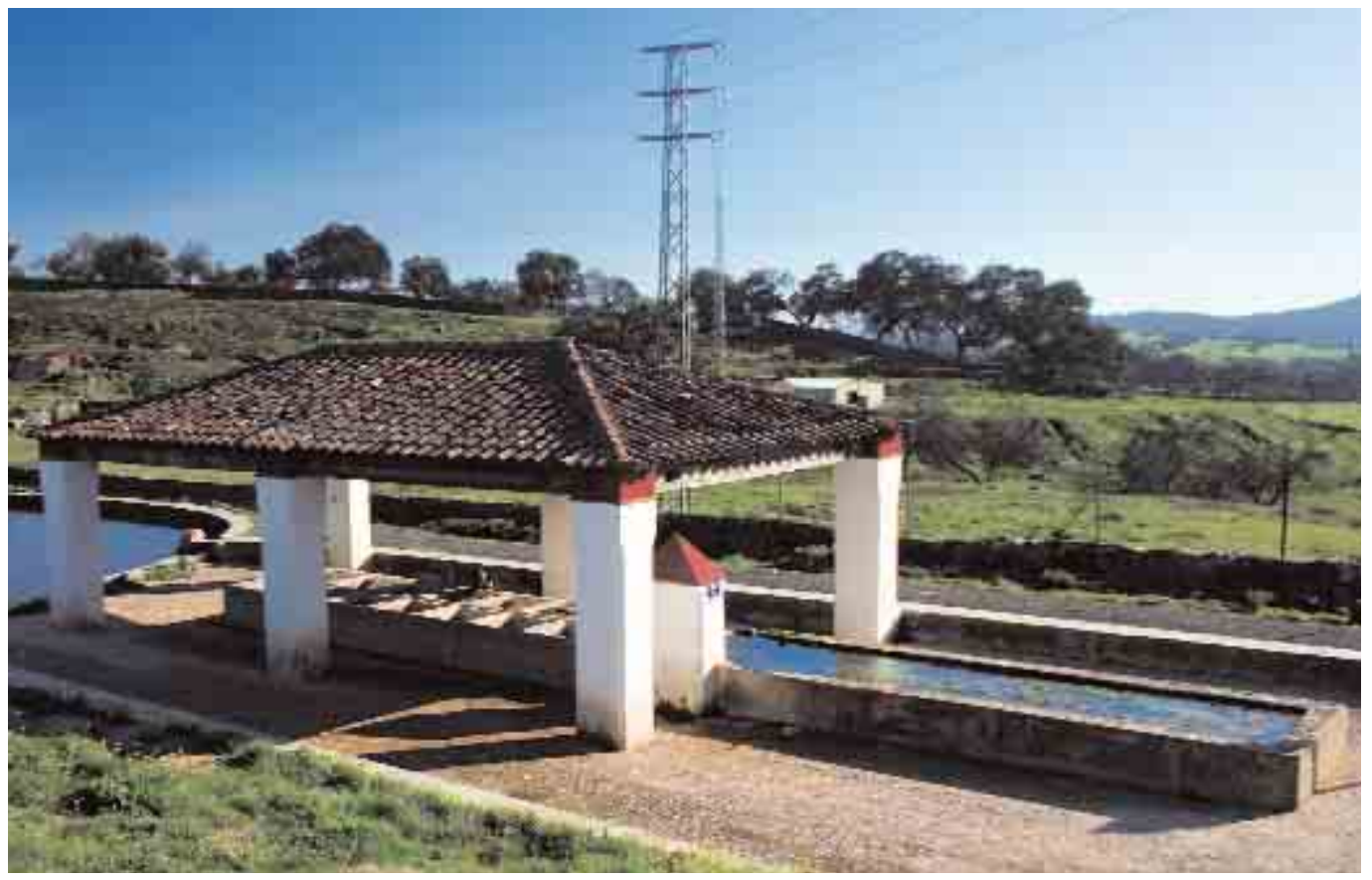

(1) Fuente de La Alguera. Aracena. 2007 / JAVIER Romero, IAPH 